\title{
Recursos para el relieve de inicios y cierres en la columna lingüístico-periodística
}

\author{
Resources for highlighting beginnings and \\ conclusions within language columns in the \\ press
}

\author{
Luis Cortés Rodríguez \\ Universidad de Almería, Almería, España \\ lcortes@ual.es
}

TACCESO ABIERTO / OPEN ACCESS

Cita: Cortés Rodríguez, Luis (2020). Recursos para el relieve de inicios y cierres en la columna lingüísticoperiodística. Textos en Proceso, 6(2), pp. 25-36.

https://doi.org/10.17710/tep.2020.6.

\section{3 cortes}

Editoras: Susana Guerrero Salazar y Carmen Marimón Llorca

Recibido: 30/10/2020

Aceptado: 25/11/2020

Conflicto de intereses: El autor ha declarado que no posee conflicto de intereses.

Copyright: (c) Luis Cortés Rodríguez. Esta obra está bajo licencia Creative Commons Reconocimiento 4.0

\section{Resumen}

Sabemos que el género columna periodística se presenta con una gran libertad de disposición y estilo, lo que dificulta en gran manera, dada esta diversidad, cualquier intento de regulación formal. No obstante, tras considerar una de las orientaciones sugeridas por las coordinadoras de este volumen monográfico -la que se refiere a los recursos expresivos y a las estructuras lingüístico-discursivas utilizadas en los textos periodísticos-, concebimos la posibilidad de analizar algunos aspectos que sirvieran para regular, de algún modo, las ciento dos columnas que, sobre cuestiones lingüísticas, fueron recogidas en el libro El habla nuestra de cada día (Cortés, 2019). El análisis de tales columnas mostró desde un primer momento dos ideas destacadas: $a$ ) la preocupación del autor por el relieve de inicios y cierres, y $b$ ) la repetición constante de los diferentes recursos empleados en ambas secuencias a lo largo de las columnas. El artículo analiza detenidamente cuáles fueron esos recursos y su función.

Palabras clave: columnas sobre la lengua, estructura del texto periodístico, relevancia de los inicios, relevancia de los cierres.

\section{Abstract}

The journalistic column genre has great freedom of disposition and style, which makes it very difficult to any attempt any formal regulation. However, after considering one of the guidelines suggested by the editors of this monographic volume -the one that refers to expressive resources and linguistic-discursive structures used in journalistic texts-, we conceived the possibility of analysing some aspects that would serve to regulate, in some way, the one hundred and two columns that, on linguistic issues, were collected in the book El habla nuestra de cada dia 
(Cortés, 2019). The analysis of these columns showed two outstanding ideas: a) the author's concern for the relevance of openings and closings, and b) the constant repetition of the different resources used in both sequences throughout the columns. The article takes a careful look at those resources were and their function in discourse.

Keywords: columns on language, structures journalistic texts, relevance of openings, relevance of closings.

\section{Cuestiones previas}

1.1. Vamos a tratar de columnas lingüístico-periodísticas. Y son tales por tres motivos: $a$ ) por haber sido publicadas regularmente; $b$ ) por la especial disposición del texto en su lugar de transmisión, el periódico, y c) por su contenido lingüístico. Concretamente, lo vamos a hacer de ciento dos columnas que, sobre las más diversas cuestiones relacionadas con el habla de todos los días, hemos recogido en un reciente volumen titulado, precisamente, El habla nuestra de cada día (Cortés, 2019). En su mayoría, las publicamos en el diario La Voz de Almería, especialmente desde febrero de 2009 hasta abril de 2013 ${ }^{1}$. Dado su carácter divulgador, en todos los casos pretendimos tanto la amenidad como la sencillez.

Concebimos la columna periodístico-lingüística como un recipiente en que poder divulgar determinadas consideraciones sobre temas relacionados con nuestro discurso, oral, escrito y tecnológico. Con ellas, se pretenderá enseñar un tanto y entretener otro tanto. En este sentido, siempre nos han venido y nos siguen viniendo a la mente esas palabras del Infante Don Juan Manuel en el prólogo de El Conde Lucanor, cuando desvela que para enseñar de manera deleitable imitaba la fórmula de algunos físicos:

Cuando quieren facer alguna melecina que aproveche al fígado, por razón que naturalmente el fígado se paga de las cosas dulces, mezclan con aquellas melecinas que quieren melecinar el fígado, azúcar o miel o alguna cosa dulce porque por el pagamiento que el fígado ha de la cosa dulce, en tirándola para sí, lleve con ella la melecina que le ha de aprovechar (1966 [1335], p. 14).

Una característica diferenciadora de estas columnas cuyos inicios y cierres ahora analizamos, con respecto a la larga tradición lingüístico-periodística en que cabe ubicarlas, es su temática. Muchas de ellas se basan en aspectos relacionados con cuestiones discursivas (elementos innecesarios, los mecanismos del lenguaje político o publicitario, la cortesía, la argumentación, el hablar en público, la enseñanza del discurso oral o el habla de las mujeres dirigentes, entre otros títulos), cuestiones que, por motivos que todos entendemos, no habían sido propuestas en épocas pasadas. No es, sin embargo, de la temática de lo que vamos a ocuparnos,

\footnotetext{
${ }^{1}$ En la edición del libro, las columnas no siguen el orden cronológico en que habían aparecido en la prensa, sino que se presentan reunidas temáticamente en ocho bloques: I. El bien hablar. II. Lenguajes especiales. III. Malos usos en el habla de todos los días. IV. La ortografía y algunos empleos deficientes. V. Los andaluces y sus hablas, VI. Lenguaje y sociedad. VII. Sobre enseñanza de la lengua española. VIII. Sobre herramientas para el buen uso de nuestra lengua. En el volumen, además, hallamos una introducción, un epílogo, una bibliografía sobre contenidos tratados y doscientas notas, aproximadamente, a pie de página, en las que se trata, sobre todo, de aspectos que, de una u otra manera, complementan y enriquecen lo publicado en su día en el periódico. El contenido de la columna, sin notas, tal y como esta apareció en la prensa, ocupa alrededor de 5000 caracteres con espacios. El volumen consta de 462 páginas.
} 
sino del análisis de determinados aspectos que, aun no siendo exclusivos, ni mucho menos, de estas columnas, se repiten en la mayoría de ellas hasta el punto de ser un modus operandi que las caracteriza.

1.2. El Fedro es, posiblemente, el diálogo más conocido de Platón (264c./1986). Uno de sus principios ha guiado tanto la segmentación secuencial como la conexión entre ideas a la hora de estructurar las columnas que analizamos. Tal principio apunta tanto a la necesidad de una distribución en partes como a la armonía entre ellas y de todas con el conjunto: "Pero creo que me concederás que todo discurso debe estar compuesto como un organismo vivo, de forma que no sea acéfalo, ni le falten pies, sino que tenga medio y extremos, y que, al escribirlo, se combinen las partes entre sí y con el todo" (pp. 382-383).

Su aplicación nos llevó en todos los casos a una definida división secuencial tripartita: inicio, desarrollo y cierre. El desarrollo, la parte amplia, está dedicada a las más distintas cuestiones lingüístico-discursivas, todas ellas encaminadas a la reflexión del lector sobre algo que le es tan próximo y conocido como el idioma del que se vale todos los días cuando se comunica con sus amigos o expone sus opiniones en cualquier reunión. Se trata del mismo idioma que nos acompaña en nuestro quehacer cotidiano y que nos exige un buen uso de las preposiciones o de la argumentación; nos reclama un mejor conocimiento de determinados mecanismos para poder interpretar de manera acertada un discurso político o publicitario; nos demanda un empleo eficaz de los recursos de cortesía o de las argucias que nos permitan evitar, en lo posible, las muletillas, por ser elementos innecesarios, etc. Es ese mismo idioma que nos castiga diariamente con usos tan "andrajosos" como los empleados, en tantas ocasiones, en el lenguaje publicitario y jurídico. Estos y otros contenidos se presentan en muchas de las columnas recopiladas.

Siguiendo con la estructura, hay una particularidad que cabe destacar por encima de las demás: la importancia dada por el autor tanto a la secuencia inicio de cada columna, con la pretensión de evitar la huida del posible lector que se acerque a ella, como a la secuencia cierre, bien con la idea de seducir a quien hasta allí llegó o bien con el propósito de ganar su atención para la columna siguiente. De ambas secuencias y de los recursos que en ellas se emplean para sus fines, nos ocuparemos a continuación.

\section{Los inicios como incentivadores de interés y de amenidad}

\subsection{Su importancia}

Un buen inicio (exordio), dicen los manuales de Retórica, ha de intentar ganar el interés del público y ayudar a crear una buena imagen del hablante. Con él, no se ha de pensar en captar la benevolencia de los interlocutores, sino su confianza. Se ha de evitar la longitud en favor de la brevedad y explicitud; se ha de huir de lo confuso y banal en aras de la claridad. Son los primeros momentos de cualquier intervención, sea un discurso, una representación teatral o una columna periodística. Y de ahí su importancia.

En el acto V de La Celestina (1499/1969, p. 191), la vieja, tras despedirse de Melibea, anda por la calle hablando consigo misma entre dientes. Una de las frases que balbucea es esta: “ $¡ O h$ vieja Celestina, vas alegre! Sábete que la mitad está hecha cuando tienen buen principio las cosas". Las palabras de Celestina tienen 
sentido no solo aplicadas a los negocios de la alcahueta, sino, en buena parte, para un redactor de columnas periodísticas. En estas, se habrá de evitar, en lo posible, algo tan importante como que el lector, siempre tan atareado, deje su lectura al poco de empezarla. No sabemos si el inicio de una columna, como dicen algunos tratadistas, ha de ser lo último que se redacte, pero sí que es la secuencia que ha de hacerse con más mimo, con más cuidado, con más atención.

\subsection{Recursos}

Han sido seis los recursos empleados con la finalidad de evitar, en lo posible, esa aludida y preocupante deserción de lectores. Entre ellos, aunque discutible, hemos considerado los veintidós inicios en los que el autor consideró más eficaz y atractivo para el lector, el dar el protagonismo a la relación entre la columna presentada y la anterior de semejante temática. Al margen de tal recurso, los cinco restantes utilizados en la búsqueda de esa amenidad fueron a) las citas, generalmente literarias; b) algunos dichos y sus orígenes; c) noticias sobre hechos recientes; $d$ ) alguna experiencia personal, y e) correspondencia de lectores. Sus cifras de empleo fueron estas:

Tabla 1. Recursos utilizados en los inicios de las columnas

\begin{tabular}{|l|l|l|l|l|l|l|l|}
\hline Recurso & Citas & Dichos y su porqué & Noticias & Personal & Lectores & Mismo tema anterior & Total \\
\hline $\begin{array}{l}\text { N. }{ }^{\mathbf{0}} \text { de } \\
\text { apariciones }\end{array}$ & 30 & 16 & 14 & 12 & 8 & 22 & 102 \\
\hline
\end{tabular}

Exceptuados los casos en que se inicia aludiendo al tema de la columna anterior, nos ocuparemos de los tres recursos más aplicados: las citas, los dichos y su porqué y las noticias sobre hechos recientes. Obviamente, en todos los casos tales inicios tenían una relación muy directa con el tema que se iba a tratar. De cada uno hemos seleccionado dos casos para su explicación.

\subsubsection{Citas}

Las citas son en su mayoría literarias, si bien hay otras de personajes como Aristóteles o Emilio Castelar, entre otros.

El primer caso al que vamos a aludir se encuentra en la columna 35. "La cultura y los debates en torno al estado de la nación. I" (23/01/2012, pp.159-161)2. Es la primera de las tres que dedicamos al escaso espacio concedido en los debates anuales del estado de la nación ${ }^{3}$ al tema cultural, tanto por quienes están en el poder como por quienes permanecen en la oposición. El tiempo que se dedica a esta cuestión, cuando se hace, resulta exiguo. Esto, obviamente, nos lleva, como autor de la columna a una actitud de pesadumbre e incredulidad. Para tal inicio nos hemos valido de Ángel Ganivet y de sus Cartas finlandesas (1898), concretamente de esta cita que, posiblemente, desconozcan nuestros políticos: "Un pueblo culto es un pueblo libre; un pueblo salvaje es un pueblo esclavo, y un pueblo instruido á la

\footnotetext{
${ }^{2}$ De cada columna citaremos su fecha de publicación en el periódico y las páginas ocupadas en el libro El habla nuestra de cada día. En este caso: publicada el 23 de enero de 2012, pp. 159-161.

${ }^{3}$ Los debates del estado de la nación fueron implantados por Felipe González, en 1983. Se celebran anualmente, exceptuados los años de elecciones. Según dijo su instaurador (presidente por entonces del gobierno español) era una experiencia nueva, que habría que repetir en años posteriores; de igual manera se ha venido haciendo hasta 2015. En total, veinticinco debates. Desde 2016, por diversos motivos, no se han celebrado.
} 
ligera, á paso de carga, es un pueblo ingobernable" (p. 32). Ante ello, cabe preguntarse si no seríamos más libres si fuéramos más cultos y si no seríamos más cultos si los gobiernos acercaran y propiciaran los contenidos culturales. Una muestra de dicho interés debería estar en su atención destacada en un debate anual de estas características. Y esto no existe.

El segundo ejemplo de cita lo encontramos en la columna 38. "Los halagos a los españoles en los cierres de los discursos políticos" (10/12/2012, pp. 171-173). En esta ocasión, lo aludido es el argumento de una obra literaria conocida. Es de Lope de Rueda, el autor de comedias, farsas y pasos al que todas las ciudades españolas tienen dedicada su calle, aunque ninguna haya dado el nombre a sus teatros. Uno de sus pasos se tituló La tierra de Jauja (en torno a 1560/2005). En él, dos ladrones pretenden robar una cazuela de comida a un simplón llamado Mendrugo. Para embobarlo le hablan de Jauja, una tierra bella en la que las calles están pavimentadas con yemas de huevo, los árboles dan buñuelos, los ríos, leche, etc. Al iniciar la columna con este argumento se aspira a presentar la cuestión relacionada con el lenguaje político que hemos de tratar: los cierres de los discursos de los presidentes de los diferentes gobiernos españoles en los debates del estado de la nación. Tales discursos, en este siglo, fueron emitidos por Aznar (2001, 2002 y 2003), Zapatero (2005, 2006, 2007, 2009, 2010 y 2011) y Rajoy (2013, 2014 y 2015). En la mayoría de ellos, hay un momento que se dedica al halago de los españoles: su inteligencia, su madurez, su esfuerzo, etc., lo que nos recuerda el paso de Lope de Rueda. Decimos esto porque para Aznar, en 2002, por ejemplo, España es un país cuya sociedad es "más libre, más fuerte, más desarrollada y más decidida a seguir avanzando". Zapatero, en 2005, ha comprobado muchas veces, en su primer año de mandato, "lo inteligentes, lo sensatos" y todo lo demás que se quiera que somos los españoles. Solo les faltó decir a uno y otro que gracias a esos españoles los árboles daban buñuelos y los ríos leche. Recordemos que las citas en el inicio se repiten en treinta columnas (29.4\%).

\subsubsection{El porqué de ciertos dichos}

Es fácil pensar en la ayuda que en este apartado del inicio nos prestaron, especialmente, los libros de Candón y Bonnet (1993) e Iribarren (1994) y, en menor medida, los de Rodríguez Plasencia (1997) y Buitrago (2012). En todas las ocasiones, al igual que en el anterior y a diferencia del apartado siguiente, primero considerábamos el tema que queríamos tratar y, posteriormente, se buscaba la cita $\mathrm{o}$, en este caso, el dicho que entroncara con la cuestión. El primero de los dos hechos con que vamos a ejemplificar este aspecto aparece en la columna 50. "La absurda moda de los kit, set, pack o stock. I" (05/09/2011, pp. 219-221). Se acomete el tema de la necesaria incorporación de vocablos extranjeros a nuestra lengua y las condiciones requeridas para tal agregación. Tras reiterar la necesidad de la anexión de nuevos vocablos de otras lenguas, pues nuestro idioma difícilmente podría sobrevivir muchos años sin tal acogida, se defenderá en la columna la manera adecuada en que dicha incorporación se ha de llevar a cabo, que nunca podrá ser $a$ ojo de buen cubero. Buscando esa amenidad inicial, comenzamos explicando el origen de la citada frase "A ojo de buen cubero", que, según Candón y Bonnet (1993, p. 98), estaba en la falta de reglamentación que antiguamente existía en los diferentes reinos a propósito de las medidas. Las cubas, que eran los recipientes de madera que servían para contener agua, vino, aceite u otros líquidos, tenían unas 
medidas de capacidad que variaban según que el cubero que las hubiera fabricado perteneciera a uno u otro reino. Con la historia se da inicio a la columna.

El segundo dicho que nos sirve de ejemplo se encuentra en la columna 43. "Elementos innecesarios. I" (08/06/2009, pp. 191-193). Es la primera de las dos que atienden a una forma extendida de deslustrar nuestra habla: el empleo de términos innecesarios, que, no solo están vacíos de significado concreto, sino que son como parásitos que se instalan en los enunciados sin que nadie los haya invitado. Y para dar inicio a esta cuestión nos valimos de un dicho introductorio de ambas columnas: “Aquí estamos todos, dijo el duende”. Cuenta Iribarren (1994, p. 150) que había un duende en una casa y que hacía tantas diabluras al dueño de la vivienda, escondiendo unas cosas o rompiendo otras, que el inquilino, por alejarse de él, se mudó a otra morada. Cuando creyó haber terminado la mudanza y le preguntó a su mujer si faltaba algo por trasladar al nuevo hogar, se oyó la vocecilla del duende, que, escondido en un palanganero, decía una y otra vez: “Acá estamos todos”, y de aquí procede la frase popular. Esta suele decirla el que llega a un sitio donde no se cuenta con él. Pues bien, tal es la sensación que nos producen esos elementos innecesarios, esas muletillas, la verdad que, pues bueno, a veces en forma de apéndice del tipo ¿sabes lo que te digo?, ¿me entiendes?, ¿vale?, etc., que no significan nada, que nadie los espera, pero que se presentan, como el duende, sin haber sido invitados. Y, lo que es peor, con demasiada frecuencia. Estos dichos se dieron en el inicio de dieciséis columnas (15.7\%).

\subsubsection{Noticias sobre hechos acontecidos recientemente}

Estas noticias, a diferencia de los apartados anteriores, sí fueron las que nos sugirieron la cuestión que posteriormente trataríamos en las catorce columnas en que se mostraron. Así, la columna n. ${ }^{\circ}$. "La ministra y el bien hablar" (03/02/2009, pp. 23-25) surge como resultado de una información aparecida, días antes, en la prensa. Una parlamentaria catalana, Montserrat Nebrera, con motivo de los problemas acaecidos en el aeropuerto de Barajas, en Madrid, tuvo la idea de burlarse de la manera de hablar de la ministra de Fomento del Gobierno de España, Magdalena Álvarez, por su condición de andaluza. Con nuestra columna, intentamos explicar el error de aquel juicio de la parlamentaria. Hablamos de la existencia de dos normas del español hablado: la castellana y la andaluza, sin que quepa considerar que una sea superior a la otra, pues cada una tiene sus particularidades. Por tanto, no hay, en principio, argumentos para defender que se hable mejor por haber nacido en Sevilla o en Lugo, en Madrid o en Murcia. Lo que sí hay, sin embargo, son variantes más apartadas de la norma estándar -¿las más cerradas?- que tienen menos prestigio social, y estas pueden ser emitidas por hablantes gallegos, aragoneses, vascos, catalanes, pasiegos y, claro está, por andaluces, si bien es verdad que, desgraciadamente, por demasiados andaluces. La noticia nos había inspirado la columna y su posición inicial creemos que podría atraer la atención del lector.

La segunda noticia de actualidad con la que vamos a ejemplificar aparece en la columna 2. "De nuevo sobre el bien hablar" (24/05/2009, pp. 27-30). Tal noticia vino dada por la presencia, aquella semana, en nuestra universidad, la Universidad de Almería, de Manuel Campo Vidal, periodista prestigioso y, entonces, Presidente de la Academia de las Ciencias y las Artes de Televisión de España, quien habló de la comunicación oral. La citada actividad académica cabía considerarla, y así lo hicimos, como oportuna. Y esto nos llevó a escribir acerca de la necesidad de que 
la enseñanza de la lengua oral dejara de ser el pariente pobre de nuestro sistema educativo en sus distintos niveles ${ }^{4}$. Sabido es que tal enseñanza estaba reducida en nuestro país a cursos, vídeos de internet o libros con títulos como "Hablar bien en público", "Cómo comunicarse bien en público", "Cómo ser más eficaz a la hora de hablar en público", etc. En la mayoría de ellos se nos explican las mismas cuestiones: cómo vencer el miedo, las fases de la preparación del tema, etc., pero nada se nos dice, entre otras cosas, de los marcadores que conectan las ideas y de su modo de empleo, de la omisión de expletivos y muletillas o de la diferencia entre silencios venidos y buscados. Y esto, hoy, gracias a los avances aportados por los estudiosos del discurso oral, se conoce y se puede y debe aplicar en una programada enseñanza de la lengua oral en los diferentes niveles docentes. Tales noticias aparecieron en los inicios de catorce columnas (13.7\%).

\section{Cierres}

\subsection{Su importancia}

Señalaba Quintiliano ${ }^{5}$ que, si bien se tenderá en todas las partes del discurso a mantener vivos los mensajes, el orador ha de tener una preocupación mayor al inicio de su intervención y, de manera muy especial, en la peroración final, parte dominada por la enfatización de los procedimientos. No creemos, sin embargo, que podamos hablar de esta prioridad en la columna periodística, pues, como hemos ya indicado, la atención del lector corre el peligro de dispersarse antes que la del oyente, por lo que nada hay tan urgente como atraer a aquel en el inicio. No obstante, hemos de pensar que el cierre de una columna - como el de un discurso, un concierto musical o el de un espectáculo circense- siempre ha de merecer un trato especial, pues el lector que haya llegado hasta aquí se verá en buena manera influido por ese final a la hora de forjar su juicio, más o menos positivo o negativo, de la columna acabada.

La secuencia cierre, normalmente, suele envolver una implicación aún mayor del autor ante la defensa del tema tratado, si bien no cabe olvidar que en la columna periodística $^{6}$, al ser un comentario personal sobre una determinada cuestión considerada de interés -en este caso lingüístico-, siempre existirá alguna implicación. En el refuerzo de esta, se vuelcan los dos ingredientes propios de la secuencia cierre: lo eficaz y lo estético. Esto se suele conseguir no tanto con un resumen claro de lo dicho previamente dada la brevedad del género, cuanto con el intento de premiar al lector moviendo su ánimo. Y este aspecto, persuasivo-estético, se conseguirá a través del empleo de ciertos recursos.

\subsection{Recursos}

Decíamos que el autor para conseguir un cierre con un determinado grado persuasivo-estético se ha de valer de recursos. Por orden de frecuencia, estos fueron

\footnotetext{
${ }^{4}$ La necesidad de esta enseñanza en los distintos niveles de nuestro sistema educativo es una cuestión que nos ha ocupado durante años (entre las aportaciones más recientes: Cortés $(2017,2018)$ o Cortés y Muñío (2012)). Un artículo sobre esta urgencia apareció publicado en el diario El País, el 9 de agosto de 2012, y recogido en el libro, en pp. 377-380, con el título: «La enseñanza de la lengua oral».

5 Admirador de la obra de Cicerón, siempre consideró que tras las aportaciones de este eran innecesarios nuevos tratados de Oratoria. La obra de Quintiliano que hoy conocemos sobre esta cuestión, Institutio oratoria, es resultado de los apuntes recogidos por sus alumnos. Se imprimió por vez primera en la editorial de Antonio Campano, en Roma, en 1470.

${ }^{6}$ Un resumen claro sobre la columna periodística se puede encontrar en el capítulo II del libro de Mancera (2009, pp. 35-54).
} 
los empleados en las columnas analizadas: a) el dictamen final del autor, a modo de juicio o sentencia; $b$ ) la cita, generalmente literaria, condensadora de la cuestión, c) el anuncio del capítulo siguiente en aquellos temas que constaban de varias columnas, y $d$ ) un apunte irónico. En el primero de ellos, es como si el autor, preocupado hasta ahora de atenuar su compromiso con lo dicho, decidiera mostrar que él también juzga acerca de lo que se ha tratado hasta ese momento. Esto no implica el cambio de pronombres del nosotros al yo como ocurre, por ejemplo, en los actos finales de los enunciados políticos (aunque sí pueda darse en alguna ocasión, no sé si... pero). Lo más normal, no obstante, es que se siga manteniendo, en general esa segunda persona mediante repetidos inicios del tipo: todos sabemos..., hemos de pensar..., no hemos de olvidar..., no sabemos... pero sí, ojalá...; es verdad que... pero nosotros... y algunos más.

Los procedimientos citados se encuentran en noventa y nueve de las ciento dos columnas. Si exceptuamos de esta cifra las veintiséis ocasiones en las que el dictamen final del autor se da en solitario, en las setenta y tres restantes sí que aparecen dos o más de tales recursos en un mismo cierre:

Tabla 2. Número de recursos en los cierres de las columnas

\begin{tabular}{|l|l|l|l|l|l|l|}
\hline N. ${ }^{\mathbf{0}}$ recursos & 1 & 2 & 3 & 4 & 5 & Ninguno \\
\hline N. ${ }^{\mathbf{0}}$ columnas & 26 & 37 & 29 & 5 & 2 & 3 \\
\hline
\end{tabular}

Las posibilidades de combinación y de orden de los citados recursos nos ofrecieron un número amplio de estructuras de aparición, concretamente diecinueve, como podemos ver en la tabla $n .^{0} 3^{7}$ :

Tabla 3. Combinaciones de recursos y sus cifras en los cierres

\begin{tabular}{|c|c|c|c|c|c|c|c|}
\hline Recurso & $\begin{array}{l}\text { Dictam.autor } \\
\text { +apunte } \\
\text { irónico } \\
\end{array}$ & $\begin{array}{l}\text { Dictam.autor } \\
\text { +cita } \\
\text { +apunte irónico }\end{array}$ & $\begin{array}{l}\text { Cita } \\
\text { +autor }\end{array}$ & $\begin{array}{l}\text { Dictamen } \\
\text { autor } \\
+ \text { anuncio } \\
\end{array}$ & $\begin{array}{l}\text { Dictam.autor } \\
+ \text { cita } \\
\text { +dictam.autor } \\
\end{array}$ & $\begin{array}{l}\text { Dictam.autor } \\
+ \text { cita }\end{array}$ & $\begin{array}{l}\text { Dictam.autor } \\
+ \text { cita } \\
+ \text { anuncio } \\
\end{array}$ \\
\hline N. ${ }^{0}$ casos & 14 & 10 & 10 & 7 & 6 & 5 & 4 \\
\hline Columnas & $\begin{array}{l}9,11,15,16, \\
20,21,34,38, \\
39,47,71,82, \\
93,98\end{array}$ & $\begin{array}{l}49,13,33,37 \\
49,50,72,88, \\
92,102\end{array}$ & $\begin{array}{l}1,29,45, \\
54,57,58,61, \\
77,83,84\end{array}$ & $\begin{array}{l}2,6,46,59 \\
65,66,76\end{array}$ & $\begin{array}{l}3,5,14,22 \\
63,87\end{array}$ & $\begin{array}{l}17,18,32, \\
39,86\end{array}$ & $10,75,89,99$ \\
\hline Recurso & $\begin{array}{l}\text { Cita } \\
\text { +dictam.autor } \\
\text { +apunte } \\
\text { irónico }\end{array}$ & $\begin{array}{l}\text { Dictam.autor } \\
+ \text { cita } \\
\text { +dictam.autor } \\
+ \text { anuncio }\end{array}$ & $\begin{array}{l}\text { Dictam.autor } \\
\text { +cita } \\
\text { +dictam.autor } \\
\text { +apunte } \\
\text { irónico } \\
\end{array}$ & $\begin{array}{l}\text { Cita } \\
\text { +dictam.autor } \\
\text { +anuncio }\end{array}$ & $\begin{array}{l}\text { Cita } \\
+ \text { dictam.autor } \\
+ \text { cita }\end{array}$ & $\begin{array}{l}\text { Cita } \\
\text { +anuncio }\end{array}$ & $\begin{array}{l}\text { Anuncio } \\
\text { +dictam.autor } \\
\text { +apunte } \\
\text { irónico }\end{array}$ \\
\hline N.o casos & 3 & 2 & 2 & 2 & 1 & 1 & 1 \\
\hline Columnas & $55,69,85$ & 7,81 & 24,36 & 35,43 & 8 & 25 & 91 \\
\hline Recurso & $\begin{array}{l}\text { Anuncio } \\
+ \text { cita } \\
\text { +apunte } \\
\text { irónico }\end{array}$ & $\begin{array}{l}\text { Cita } \\
\text { +dictam.autor } \\
\text { +anuncio } \\
\text { +apunte irónico }\end{array}$ & $\begin{array}{l}\text { Anuncio } \\
+ \text { dictam.autor } \\
+ \text { cita }\end{array}$ & $\begin{array}{l}\text { Dictam.autor } \\
\text { +cita } \\
\text { + anuncio } \\
\text { + dictam.autor } \\
+ \text { cita }\end{array}$ & $\begin{array}{l}\text { Cita } \\
+ \text { dictam.autor } \\
+ \text { cita } \\
\text { +dictam.autor }\end{array}$ & Dictam.autor & Ninguno \\
\hline N. ${ }^{\circ}$ casos & 1 & 1 & 1 & 1 & 1 & 26 & 3 \\
\hline
\end{tabular}

\footnotetext{
${ }^{7}$ En esta tabla 3, los diferentes tonos de grises marcan el número de recursos empleados en las columnas y que aumentan según se oscurece dicho tono: de dos, el más claro, a cinco el más oscuro.
} 


\begin{tabular}{|l|l|l|l|l|l|l|l|}
\hline Columnas & 27 & 44 & 56 & 90 & 79 & Restantes $^{8}$ & $48,68,101$ \\
\hline
\end{tabular}

De todas estas combinaciones, nos ocuparemos solo de las que emplean dos y tres recursos conjuntamente, las cuales, evidentemente, son las más utilizadas 9 .

\subsubsection{Cierres con dos recursos}

Hubo treinta y siete columnas $(36.3 \%)$ que se cerraron con dos de estos procedimientos, si bien se presentaron en cinco distintas combinaciones:

Tabla 4. Cierres con dos elementos: recursos y su combinación en las apariciones

\begin{tabular}{|l|l|l|l|l|l|}
\hline Recurso & $\begin{array}{l}\text { Dictamen autor } \\
+ \text { apunte irónico }\end{array}$ & $\begin{array}{l}\text { Cita } \\
+ \text { dictamen autor }\end{array}$ & $\begin{array}{l}\text { Dictamen autor } \\
\text { +anuncio }\end{array}$ & $\begin{array}{l}\text { Dictamen autor } \\
+ \text { cita }\end{array}$ & $\begin{array}{l}\text { Cita } \\
\text { +anuncio }\end{array}$ \\
\hline N. ${ }^{\circ}$ casos & 14 & 10 & 7 & 5 & 1 \\
\hline Columnas & $\begin{array}{l}9,11,15,16,20, \\
21,34,38,39,47,\end{array}$ & $\begin{array}{l}1,29,45,54,57, \\
58,61,77,83,84\end{array}$ & $\begin{array}{l}2,6,46,59,65, \\
66,76\end{array}$ & $17,18,32,39,86$ & 25 \\
& & & \\
\hline
\end{tabular}

La tabla nos muestra que el orden dictamen del autor+apunte irónico es el que con más frecuencia se ha dado (catorce casos). Para ejemplificar tal hecho nos vamos a valer de dos cierres. En la columna 20, "El extraño lenguaje jurídico. II" (29/08/2009, pp. 103-105), el autor, tras haberse referido a diversos ejemplos que prueban las dificultades a la hora de entender tal tipo de lenguaje, habla de la favorable función que en Francia lleva a cabo el Alto Órgano (Conseil supérieur de la magistrature, en francés, CSM). Se inicia el citado dictamen con una de las fórmulas iniciales repetidas en este punto por parte del autor, «no sé si...» para que, posteriormente, este 'sospeche' de su inexistencia en España: "No sé si en España hay también algún Alto Órgano que se ocupe de estas cuestiones, si bien los datos recogidos al azar y aportados en el artículo anterior y en este no parecen sospechar su existencia. Es un campo en el que los filólogos tendrían que colaborar con los juristas". Tras lo cual, inicia la ironía, pues resulta obvio que nadie puede estar de acuerdo con lo sugerido ni produciría divertimiento alguno: "Salvo que todos,

${ }^{8}$ Concretamente estas: $12,19,23,28,30,31,40,41,42,51,52,53,60,62,64,67,70,73,74,78,80$, 94, 95, 96, 97, 100 .

${ }^{9}$ Los otros dos tipos, con cuatro y cinco recursos, solo los encontramos en siete columnas $(6.9 \%)$. En cinco de ellas, se produjo el agrupamiento de cuatro, que ocasionaron tres diferentes disposiciones. En las dos restantes (parte baja de la tabla), se llegó a los cinco, con dos disposiciones distintas:

Tabla i. Cierres con cuatro y cinco elementos

\begin{tabular}{|l|l|l|l|}
\hline Recurso & $\begin{array}{l}\text { Dictamen autor } \\
\text { +dictamen autor } \\
\text { +anuncio }\end{array}$ & $\begin{array}{l}\text { Dictamen autor } \\
+ \text { cita } \\
\text { +apunte irónico }\end{array}$ & $\begin{array}{l}\text { Cita } \\
\text { +dictamen autor } \\
\text { +dictamen autor }\end{array}$ \\
\hline $\mathbf{N .}^{\mathbf{0}}$ casos & 2 & 2 & 1 \\
\hline Columnas & 7.81 & 24.36 & 44 \\
\hline \multicolumn{3}{|l|}{} \\
\hline Recurso & $\begin{array}{l}\text { Cita } \\
+ \text { dictamen autor } \\
\text { +cita } \\
+ \text { dictamen autor } \\
\text { +apunte irónico }\end{array}$ & $\begin{array}{l}\text { Dictamen autor } \\
+ \text { cita } \\
\text { +anuncio } \\
+ \text { dictamen autor } \\
\text { +cita }\end{array}$ & \\
\hline $\mathbf{N}^{\mathbf{0}}$ casos & 1 & 1 & \\
\hline Columnas & 79 & 90 & \\
\hline
\end{tabular}


legisladores, jueces, usuarios, estemos de acuerdo en que unos redacten mal para que otros entendamos peor. ¡Chocante divertimiento!”.

Le sigue en importancia, dentro de esta combinación de dos elementos, la estructura cita+dictamen final de autor, con nueve apariciones. La columna 54. "Desprecio de lengua y alabanza de dejadez y aceleración. I" (03/10/2011, pp. 237239) es un ejemplo de ello. Se ocupa de una carta de la presidenta de la Comunidad de Madrid, Esperanza Aguirre, a los profesores de dicha Comunidad. La carta muestra, desgraciadamente, lo que no debería ser un escrito, pues en ella hay lugar para deficiencias tanto de estilo como ortográficas. Por ello, nos parece oportuno recordarle, ante tal desaguisado, una cita de El Quijote, con el que iniciamos nuestro final de columna: "Dicen las letras que sin ellas no se podrían sustentar las armas, porque la guerra también tiene sus leyes y está sujeta a ellas y que las leyes caen debajo de lo que son letras y letrados" (Don Quijote, cap. XXXVIII, I, p. 469), columna que se termina con el dictamen final del autor sobre tal dejadez:

Presidenta, ¿cómo van a entender lo que usted les dice, si se lo dice tan mal? Atienda a la súplica, Sra. Aguirre, pues aun sabiendo que se debe a un error, en él está, sin duda, la dejadez por el buen uso de la lengua. ¿O no? Señora, si quiere que sus funcionarios sean diligentes, reflexivos y cumplidores, empiece usted a dar ejemplo. Pues eso.

Un caso con los mismos recursos se muestra en una columna previamente citada, la columna 1. "La ministra y el bien hablar" (03/02/2009, pp. 23-25). El autor piensa que, al haberse aireado por parte de los políticos la cuestión sobre el habla de los andaluces y, en general, sobre el mal empleo del discurso oral por los españoles, tal polémica puede servir para dar remedio al problema y mejorar tal deficiencia a través de su enseñanza. Para presentar esta idea, el autor se vale de una cita sacada de la parte final del capítulo XV de la primera parte de El Quijote. El caballero dice a Sancho algo que vendría bien aplicar: cualquier acontecimiento negativo siempre es susceptible de remedio: "Siempre deja la ventura una puerta abierta en las desdichas para dar remedio a ellas" (Cervantes, 1978, I, XV, p. 196). A lo que sigue, como remate del cierre, el dictamen del autor: “¿Serán venturosos nuestros polemistas y tomarán la ocasión de la desdicha para dar remedio a ella? Me temo que no. Es más, en unos días nadie se acordará del caso y nuestros estudiantes seguirán sin saber cómo hablar bien en situaciones formales. Sería maravilloso que me equivocara".

\subsubsection{Cierres con tres recursos}

En veintinueve columnas $(28.4 \%)$ se dieron tres recursos, que se distribuyeron en nueve combinaciones distintas:

Tabla 5. Cierres con tres elementos: recursos y su combinación en las apariciones

\begin{tabular}{|c|c|c|c|c|c|}
\hline Recurso & $\begin{array}{l}\text { Dictamen autor } \\
+ \text { cita } \\
+ \text { apunte irónico } \\
\end{array}$ & $\begin{array}{l}\text { Dictamen autor } \\
+ \text { cita } \\
+ \text { dictamen autor }\end{array}$ & $\begin{array}{l}\text { Dictamen autor } \\
+ \text { cita } \\
+ \text { anuncio } \\
\end{array}$ & $\begin{array}{l}\text { Cita } \\
\text { +dictamen autor } \\
\text { +apunte irónico }\end{array}$ & $\begin{array}{l}\text { Cita } \\
+ \text { dictamen autor } \\
+ \text { anuncio }\end{array}$ \\
\hline N. ${ }^{0}$ casos & 10 & 6 & 4 & 3 & 2 \\
\hline Columnas & $\begin{array}{l}49,13,33,37, \\
49,50,72,88, \\
92,102\end{array}$ & $\begin{array}{l}3,5,14,22,63 \\
87\end{array}$ & $10,75,89,99$ & $55,69,85$ & 35,43 \\
\hline Recurso & Cita & Anuncio & Anuncio & Anuncio & Cita \\
\hline
\end{tabular}




\begin{tabular}{|l|l|l|l|l|l|}
\hline & $\begin{array}{l}\text { +dictamen autor } \\
\text { +cita }\end{array}$ & $\begin{array}{l}\text { +dictamen autor } \\
\text { +apunte irónico }\end{array}$ & $\begin{array}{l}\text { +cita } \\
+ \text { apunte irónico }\end{array}$ & $\begin{array}{l}\text { +dictamen autor } \\
\text { +cita }\end{array}$ & $\begin{array}{l}\text { +dictamen autor } \\
\text { +cita }\end{array}$ \\
\hline N. ${ }^{\circ}$ casos & 1 & 1 & 1 & 1 & 1 \\
\hline Columnas & 8 & 91 & 27 & 56 & 8 \\
\hline
\end{tabular}

$\mathrm{Al}$ observar la tabla, podemos ver que la combinación más repetida fue la de dictamen final del autor + cita+apunte irónico, que encontramos en diez columnas, de las cuales vamos a referirnos a dos de ellas.

La primera es la número 49. "[...] ¿Sabes lo que te digo? [...] ¿Vale?" (02/05/2011, pp. 215-217). El autor lamenta el empleo repetido del ¿vale? a la hora de finalizar cualquier enunciado, queja que se enfatiza cuando tal uso adquiere un tono amenazante. El cierre se inicia con este dictamen: "La persona que la emite, ignorando su mal estilo, aparenta sentirse orgullosa de su opinión y la apostilla con este ¿vale?, paladín de tan preclaro juicio. Su utilización empequeñece a quien la dice a la par que ennegrece su forma de hablar", y se sigue con una cita de El Quijote en la que Sancho lamenta el empleo de amenazas:

Al oír estos últimos vales, solo me viene a la mente la respuesta que dio Sancho al cura cuando este lo amenaza con acusarlo de ladrón si no le dice dónde está su amo. Y Sancho respondió de esta guisa: «No hay para qué conmigo amenazas, que yo no soy hombre de robo, ni mato a nadie. A cada uno mate su ventura o Dios que le hizo» (Cervantes, 1978, I, XXVI).

Se cierra con el apunte irónico, en el que el autor hace uso del tan criticado empleo del ¿vale?: "Pues eso, ¿vale?”.

El segundo caso con el que vamos a ejemplificar aparece en la columna 92. "Herramientas para el mejor uso del español: diccionarios de dudas y libros de estilo. IV" (15/12/2010, pp. 395-397). El columnista asocia estos libros de estilo, en cuanto a su intención, con la de aquellos literatos que, en épocas pasadas, esbozaron algunos rasgos de un buen estilo literario: "Estos libros de ahora nos recuerdan otros 'libros de estilo': los que a lo largo de la historia han pergeñado nuestros literatos con sus consejos y preferencias".

Al desarrollar tal idea, el autor se dirige a lector para recordarle algunos ejemplos de esta preocupación:

¿Recuerdan al Infante Don Juan Manuel -nuestro mayor prosista del siglo XIVcuando considera como una de las características del buen estilo el que este se exprese «En las menos palabras que pueden seer?». ¿Han olvidado a Garcilaso de la Vega, el autor de los mejores sonetos del siglo XVI, a quien su libro de estilo lo lleva a preferir aquella forma de escritura que consigue «Huyr del afectación sin dar consigo en ninguna sequedad?», ¿Han echado en olvido a Fray Luis de León para quien hablar «No es común, sino negocio de particular juyzio, ansí en lo que se dize como en la manera como se dize; y negocio que de las palabras... elige las que convienen...; y las pesa y las mide».

Los casos aludidos parecen suficientes, dado que ha citado a tres autores de gran prestigio y, sin duda, conocidos por los lectores. No obstante, recurre a la ironía para apostillar: "Solo hemos citado tres ejemplos. ¿Acaso no son suficientes?". Evidentemente que lo son.

\section{Conclusiones}

Ya señalamos que el acercamiento a las columnas indicadas ofreció dos aspectos destacados: $a$ ) la preocupación del autor por el relieve de inicios y cierres, y $b$ ) la 
variedad de los recursos empleados en una y otra secuencia. Así, hemos podido observar que para los inicios el autor se vale, por encima de los demás recursos de relieve, de las citas, en general, literarias, que utilizó en 30 columnas, casi en un tercio de las recopiladas. El siguiente mecanismo, en la búsqueda de ese relieve conducente a la amenidad y a evitar el abandono del lector, fue la explicación del origen de algunos dichos, dichos que, al igual que las citas, entroncaban con el tema que se iba a tratar. Se presentaron en dieciséis columnas. Las noticias acontecidas en fechas cercanas, algunos aspectos personales o la correspondencia de algún lector fueron otros tantos recursos empleados. También los cierres contaron con sus recursos, repetidos una y otra vez, en especial el dictamen del autor. Este se dio en noventa y siete columnas. Únicamente se prescindió de él en los números 25 , donde se empleó cita+anuncio y 27, con anuncio + cita +apunte irónico. A estos dos casos, hay que añadir los tres en que no se recurrió a procedimiento alguno. Es más, como iniciador de esos cierres, lo encontramos en cincuenta y una ocasiones y lo hace en nueve estructuras distintas, con recursos diferentes. En importancia, le sigue la cita, hallada en cincuenta y una columnas e iniciadora del cierre en diecinueve ocasiones, con siete estructuras diferentes. Finalmente, la otra solución más empleada fue el apunte irónico, sin que haya iniciado el cierre en ocasión alguna. Sí lo hizo, en cambio, el anuncio, que, con aparición en veintiuna columnas, lo encabezó en tres ocasiones, con tres estructuras diferentes.

\section{Referencias}

1. Buitrago, A. (2012). Diccionario de dichos y frases hechas. Madrid: Espasa Libros.

2. Candón, M. y E. Bonnet (1993). A buen entendedor.... Madrid: Anaya \& Mario Muchnik.

3. Cervantes, M. de (1978 [1605-1615]). El ingenioso hidalgo Don Quijote de la Mancha., 2 vols. Colección Clásicos Castalia, 77 y 78. Madrid: Editorial Castalia. Edición, introducción y notas de Murillo, L. A.

4. Cortés, L. (2017). La enseñanza del discurso oral: pariente pobre de nuestro sistema educativo. Tonos Digital, 33. Disponible en: https://n9.cl/iq0k.

5. Cortés, L. (2018). Cómo hacer una exposición oral. Madrid: Arco Libros.

6. Cortés, L. (2019). El habla nuestra de cada día. 102 reflexiones sobre buenos y malos usos de nuestro idioma. Almería: Universidad de Almería.

7. Cortés, L. y Muñío, J. L. (2012). Mejore su discurso oral. Almería: Universidad de Almería.

8. Ganivet, Á. (1898): Cartas finlandesas. Granada: Imp. lit. y lib. Vda. é Hijos de P. V. Sabatel.

9. Infante don Juan Manuel (1966 [1335]. El Conde Lucanor, 7.. edic. Buenos Aires: Espasa Calpe Argentina.

10. Iribarren, J. M. (1994). El porqué de los dichos, 6. a edición. Pamplona: Gobierno de Navarra.

11. Lope de Rueda (2005 [en torno a 1560]). Pasos. Colección Letras Hispánicas, Madrid: Cátedra. Edición de González Ollé, F. y Tusón, V.

12. Mancera, A. (2009). 'Oralización' de la prensa española: la columna periodística. Berna: Peter Lang.

13. Platón (1986 [264c.]). Fedro. En Platón, Diálogos, Vol. 3, Biblioteca Clásica Gredos, 93, Madrid, Editorial Gredos, pp. 382-383. Traducción de Lledó Íñigo, E..

14. Rodríguez Plasencia, J.L. (1997). De tomo y lomo. El origen y significado de frases hechas. Madrid: El Drac.

15. Rojas, F. de (1969 [1499]). La Celestina, Barcelona: Círculo de Lectores. Prólogo y notas de Riquer, M. de. 